\title{
Ascesis y martirio de fin de siglo: una lectura de Éxtasis, creación dramática de Ramón Griffero
}

\author{
Jorge Rueda Castro*
}

\section{Resumen}

Éxtasis es una creación dramática que incursiona en la temática de la diseminación del sujeto y en la consecuente descentralización y debilitamiento cosmo y sociovisional a la que se enfrentan sus protagonistas. Estos últimos divagan indefectiblemente entre el des-orden precario establecido por la "condición de fin de siglo", pese al marcado anhelo de Andrés y Esteban, personajes centrales de la obra, por volverlo un orden o referente socio-religioso sustentado sobre creencias y sentimientos perennes. En la búsqueda, se dispersan entre el desencanto y la pluralidad relativa de referencias valóricas.

Palabras clave: sujeto, ideal, diseminación

\begin{abstract}
Extasis is a dramatic creation which explores into the dissemination of the individual and, as a result, into his/her decentralisation and weakening of the cosmo and sociovision faced by the protagonists. They digress inevitably in the poor dis-order established by the "end-of-century- condition", despite of Andres and Esteban's pronounced desire, main characters of the play, for turning it back to a socio-religious referent, founded on perennial beliefs and feelings. In this quest, they dissipate themselves between the disillusionment and the relative plurality of valued referencies.
\end{abstract}

Key words: individual, ideal, dissemination

* Doctor en Estudios Americanos, mención Pensamiento y Cultura. Académico Asociado del Departamento de Lingüística y Literatura, Facultad de Humanidades de la Universidad de Santiago de Chile.jorge.rueda@usach.cl 
Ascesis y martirio de fin de siglo: una lectura de Éxtasis, creación dramática de Ramón Griffero / Jorge Rueda Castro

\title{
1. Introducción
}

\author{
"Hermano cuerpo, eres fugaz \\ coyuntural, efímero, instantáneo \\ tras un jadeo acabarás inmóvil \\ y yo, que normalmente soy la vida, \\ me quedaré abrazada a tus huesitos \\ incapaz de ser alma sin tus vísceras". \\ Mario Benedetti, Desde el Alma
}

El 14 de junio de 1994 el chileno Ramón Griffero (1954) estrenó en el Festival Mundial de Dramaturgia Contemporánea, en Veroli, su obra Éxtasis, cuyo subtítulo es La senda de la santidad. Ese mismo año recibió, a propósito del impacto que provocó la escenificación de la obra en Chile, el Premio "Éxito" del Teatro Nacional Chileno. El reconocimiento de la crítica especializada rescató el novedoso sentido representacional de la obra. Esto, básicamente a través del tipo de propuesta conceptual, sintaxis dramática y la fuerza expresivo-poética tanto de los diálogos de los personajes como también de los espacios. Su autor es una figura que integró la ya mítica generación de teatristas que durante los años ochenta cambiaron el panorama del teatro chileno. Junto a Marco Antonio de la Parra, Andrés Pérez, Andrés del Bosque, Mauricio Celedón y otros, Ramón Griffero contribuyó con su dramaturgia a revisar y cambiar las bases de un lenguaje teatral que -para la década apuntada-no respondía del todo en la comprensión y en el dar cuenta de la realidad que se vivía. La superación del canon mimético fue un hecho decisivo en la configuración de un estilo diferente respecto de lo que la tradición teatral en Chile había mostrado.

Quince años después de aquel estreno, el 12 de enero de 2005, la pieza se volvió a escenificar en Santiago de Chile; la renovación del éxito de hace un decenio confirmó en ese momento la vigente significación de la obra: dar cuenta del proceso de revisión de los fundamentos de la modernidad. Con esto, las condiciones existenciales de la cultura occidental de las postrimerías del siglo pasado se proyectaban para iluminar, ahora, el primer lustro del siglo XXI. Extasis exhibe todo el doloroso camino marcado por cada una de las sendas recorridas por sus personajes centrales: Andrés y Esteban.

La teoría social que ha reflexionado sobre las características de la cultura occidental de los últimos treinta años, evaluó los aciertos y errores del pro- 
yecto occidental de la modernidad. Entre éstos, reveló cierto autoengaño en creer los grandes metarrelatos y las "certezas" desde donde surgía la idea del progreso ilimitado, basado en el formalismo, la sistematicidad ilustrada y la experimentación ${ }^{1}$.

El debilitamiento y la desesperanza constituyeron, en consecuencia, los rasgos más notorios de esta suerte de descentralización cosmo y sociovisional, cuya figura recurrente fue la búsqueda desorientada entre la pluralidad relativa de referencias valóricas.

La creación dramática de Griffero muestra, en particular, a Andrés -figura protagónica de Exxtasis-en su obsesivo deseo y ritual de alcanzar la santificación en medio de la gran ciudad (la mayoría de las veces violenta y agresiva) que, precisamente, le presenta experiencias que entorpecen todo sentido de vida y trascendencia. Su amigo, Esteban, también se embarca en esta búsqueda; lo hace desde -al revés- la materialidad que no acepta abstracciones. La urbe ${ }^{2}$, en efecto, absorbe a ambos jóvenes, en las redes sociales que la constituyen, en sus violencias y vicios, aunque también, en sus amores y fidelidades.

El presente comentario pretende examinar Éxtasis... al interior del marco recién aludido y responder, al mismo tiempo, a la pregunta que indaga por la forma cómo el texto de Griffero recompone ese contexto. Por extensión, respondería, igualmente, a la reafirmación que la obra tuvo quince años después de su estreno. Se trata, en especial, de describir el proceso social a través del cual los referentes de fin de siglo impregnan las vidas de los sujetos históricos, moldeando no sólo sus deseos y proyectos, sino también sus conductas o las "sendas" por donde caminar y cómo, en consecuencia, se reconoce en la obra una atmósfera expansiva de desencanto.

Por lo anterior, la premisa o hipótesis (entendidos como conceptos equivalentes en este artículo) que guiarán la lectura de Éxtasis o La senda de la santidad ${ }^{3}$, es que la incertidumbre, el delirio y el dolor que se reconocen en la obra, responden al ambiente de la cultura occidental de los últimos años del siglo XX (y, por extensión, no superado en los inicios del siglo XXI), momento histórico desprovisto de valores estables y precario en creencias perennes. Puntualmente, en la invención artística grifferiana, las peculiaridades del entorno de los noventa han borrado la permanencia y trascendencia del sujeto como eje y dador de sentido del mundo. Particularmente, la obra revisada refleja este

1 Al respecto, véase a Hopenhayn (2004), Larrain (1996), Vattimo (1994), Paz (1987), Lyotard (1986), entre otros.

2 Poquísimas son las pistas que entrega el texto para deducir que el espacio corresponde a Santiago de Chile. Quizás la más decidora se refiere cuando alude a la Virgen del Cerro San Cristóbal: "Reza el rosario mirando a la Virgen del Cerro", pide Andrés a otro personaje del texto (p.37).

3 Se citará según Griffero, R. (1999): Éxtasis. Recuerdos del hombre con su tortuga. Dolmen Ediciones: Santiago de Chile, pp. 15-61. La obra, en la versión editada, se organiza en función de siete "secuencias", cada una de ellas con un número irregular de escenas que las contienen. La más extensa, la secuencia cuatro, con diez escenas. La menor, la secuencia seis, con una. 
Ascesis y martirio de fin de siglo: una lectura de Éxtasis, creación dramática de Ramón Griffero / Jorge Rueda Castro

dilema en la práctica textual de Andrés y Esteban, personajes paradigmáticos de la obra; de modo que aquello que a continuación se desarrolla dará cuenta del proceso comunicacional-significativo que se genera a partir de la relación dinámica entre el texto y el contexto cultural inscrito.

Así, se partirá reconociendo que el objeto de estudio será el texto dramático, fenómeno que se sostiene sobre el fundamento que otorga el discurso escrito. La "situación discursiva de la enunciación" será la categoría de análisis capaz de dar cuenta del conjunto de circunstancias en el que se realiza el acto de comunicación de los personajes. A través de su aplicación se privilegiará: a) el entorno social en que se realiza el acto; b) la identidad de los interlocutores y, básicamente, c) la idea que cada uno de los locutores se hace del otro (Reyes, 1990: 62-88). Se sumará a estas nociones "el alcance semántico del cuerpo" (Weeks, 1997: 364-368; Muñoz, 2004) de los personajes protagónicos; esto, como aspecto esencial de la significación tutora al momento de postular una lectura de la pieza.

Junto con lo anterior, se pretende también proponer una lectura que difiera, y al mismo tiempo complemente aquéllas ofrecidas por la crítica, las cuales -contrariamente- postulan que el accionar del protagonista simboliza una respuesta alentadora a la encrucijada existencial de los años en cuestión.

Por ejemplo, Sergio Pereira (1994:33) afirma que "el camino de Andrés es una alternativa para la existencia: para vivir debe haber pasión. Andrés muere, pero su pasión lo sobrevivirá como a todos aquéllos que ponen pasión a sus actos y le dan sentido pleno a sus existencias". En esta misma línea, Yael Zaliasnik (1994:27) sostiene que "Andrés representa al joven que en este fin de siglo descubre que su único sentido es el camino de la santidad". Algo similar afirma Juan Andrés Piña (1994:57) cuando expresa que "la búsqueda del protagonista tiene que ver con unos deseos más profundos de encontrar la trascendencia y el sentido de la vida, algo que vaya más allá de las cosas mismas. Utopía, ideales, real sentido religioso son los que están en el fondo de la peregrinación de Andrés". Para Carolina Muñoz, el protagonista logra su ideal: alcanza la santidad, aunque el camino sea el martirio del cuerpo. La obra según su crítica, se organiza a partir de dos niveles de realidad, "uno de los cuales enrarece al otro redefiniendo los sentidos posibles de éste: la construcción de un proyecto espiritual ascético y la realidad cotidiana con sus diversos contenidos manifiestos". Esto hace de Andrés un "personaje alegórico ... y como tal da cuenta de una búsqueda de santidad. La senda de su santidad está dada por el martirio ... para alcanzar la unión mística o éxtasis". (2004:1-2)

\section{Andrés y Esteban: La Búsqueda}

Andrés es un muchacho que anhela lo absoluto. Con una historia de orfandad y reiterada vulnerabilidad, la figura central de la obra se ubica mirando un horizonte donde la amenaza constituye una constante. Violado en la infancia y 
huérfano, guarda el recuerdo traumático del dolor vivido por su madre, víctima constante de la agresión física provocada por el marido. De hecho, la muerte de la mujer ocurrió como consecuencia de una de las golpizas. Criado con una abuela represiva y obsesionada por la religión católica, la niñez de Andrés asimila el discurso canónico inscrito en la tradición de la moral institucionalizada.

Estos antecedentes marcan las causas del profundo sentimiento de culpa y necesidad de expiación que le motiva y, con ello, los móviles que le hacen derivar en la búsqueda de un principio que le trascienda, como promesa de una redención individual en el encuentro con un ideal universal, Dios. El recuerdo de la violación aflora permanentemente en la vida de Andrés, como una centralidad subterránea de su existencia la que le hará oscilar entre la culpa y la búsqueda de una salvación por la senda moral y religiosa:

Me dejó en calzoncillos, así contra el muro, las manos abiertas, me apretó las muñecas, sus ojos brillaban (...) Cuando estaba contra el muro y comenzó a clavarme sus alfileres en forma de cruz divisé una estampa de la última cena en la pared y mientras mordía mis testículos pensé que era un león pagano, y descubrí que el fin de mi existencia era ser un mártir (23).

Paralelamente, Esteban -amigo y confidente de Andrés- es una figura de relieve en la obra. La sensualidad desenfrenada será el signo de su vida. Al revés de Andrés, exhibirá a lo largo de la obra un proyecto que no debe nada al moralismo. Reclamará con fuerza, en efecto, la realización de un propósito basado en la competencia y superación de los otros mediante la pasión y el ansia de gozar del amor como actitud elemental con la cual enfrentar la vida:

... cuando veo alguien arriba de una moto, deseo esa moto; cuando voy a la casa de un amigo, me gusta su casa. Hasta creo que los otros hacen mejor el amor que yo. Cuando estoy con alguien, quiero estar con la de al lado... parece que todo lo que hay que vivir pasa por fuera... (18)

Voluntad de sacrificio y pasión constituyen -en Andrés y Esteban, respectivamente- imágenes singulares que aspiran a conceptos totalizadores. Ambos interpelan, a través de sus proyectos, a la posibilidad del ejercicio pleno de la condición de sujetos, y marcan la estructura básica del texto: utopías implícitas capaces de resistir las dudas y orientar sus existencias. Revelan, además, carencias que afectan a dos dimensiones contrapuestas: una global, quizás más pública, de comunicación trascendental y metafísica, de sufrimiento disciplinado, ofrendado a un ideal supremo para así remover el entorno social -en el caso de Andrés-; otra privada, de valoración afectiva e inmediata, de relación apasionada y erótica -en el caso de Esteban- .

Los desafíos que se autoimponen los dos personajes se manifiestan en los mecanismos de comunicación dialogal inicial donde se descubre, por una parte, cierta perplejidad ante una vida desprovista de sentido y de estabilidad 
Ascesis y martirio de fin de siglo: una lectura de Éxtasis, creación dramática de Ramón Griffero / Jorge Rueda Castro

y, por otra, se percibe el deseo por asumir un principio que les brinde profundización vital:

ESTEBAN: La del cine, te acuerdas, hablamos a la salida. Ella poeta, preocupada de los mares y los árboles; nos fuimos caminando... nos tomamos de las manos y un calor, fuerte, nos revolcamos en el pasto y todo daba vuelta ahhh! (...). Quiero que la conozcas, que salgamos como antes. (26)

ANDRÉS: No puedo Esteban, yo tengo otra misión, y tengo un tiempo que se me ha dado, que es irrecuperable (...)

Las tentaciones son tantas y los sacrificios tan insignificantes... Déjame, tengo que estar con Él y pensar en los que sufren. (28-29)

El esfuerzo disciplinario de Andrés y la fantasía gozosa y lúdica de Esteban concurrirán en la obra entrecruzándose o en paralelo, pero siempre en referencia o apelando a toda una gama de sentimientos y pasiones. Excitación, sacrificio, misticismo, agitación, dulzura..., todos significados que responden a la voluntad de exceder los límites y a la emergencia por construir nuevas formas que iluminen la contingencia.

\section{Construyendo sendas}

El recorrido de Andrés está dado por una red de acciones, cuyo actuar se puede seccionar en tres unidades de lectura o sendas: La piedad, El tormento y La perversión. Tales núcleos de significación, propuestas en este artículo, anudan la historia del texto y marcan las fases por las que el peregrinar del protagonista busca la revelación de su utopía.

En la primera unidad se encuentran todos los fundamentos que, con sus diferentes áreas de realidad, entrarán en contacto durante el desarrollo de la pieza. La niñez de Andrés, la violación, el sufrimiento físico de la madre, convierten al "cuerpo flagelado" en una imagen reiterada. La ira asesina del padre, las enseñanzas que la abuela hace de los martirios de Santa Lucía, Santa Rita y Santa Rosa, la lectura de la revista "Vidas Ejemplares", las pesadillas nocturnas, los sueños delirantes con ángeles, perfilan el ideal de vida ascético. Recorre los templos, canta en los coros de las iglesias y emprende la búsqueda:

Aquí estoy nuevamente ante Ti, esperando que algún día te aparezcas como lo hiciste con tantos otros. Si no, haz al menos que surjan sobre mi cuerpo las benditas llagas, don que no le negaste ni a Santa Rita ni a Santa Rosa. Señor, consolando a los afligidos y a los que sufren iniciaré el camino de la santidad. (24).

Sin embargo, la oleada secularizadora arremete e impugna las pretensiones piadosas de Andrés, lo que provoca fracturas en el personaje. El siguiente diálogo pone en entredicho un antagonismo absurdo, donde el anhelo de verdad y 
trascendencia que motiva al joven lo lleva a descubrir que esa misma "verdad" tiene para el otro un sentido divergente, pragmático y relativo, descentralizando al protagonista en su imagen de sujeto-unidad:

Entra una señora al templo cargada de paquetes. Andrés se acerca para consolarla (Acotaciones)

SEÑORA: (RECOGIENDO LA CARTERA) No tengo monedas!

ANDRÉS: No le iba a pedir.

SEÑORA: Adelante, adelante. La iglesia es bastante grande y cuando alguien se acerca si no es para pedir, es para otro tipo de intenciones (...) Yo vengo siempre, después de las compras; se me hinchan los pies y aquí aprovecho de descansar y hacer unos pedidos, es una costumbre. Usted debe andar bastante aburrido. (25)

En la cita, se descubre una situación de enunciación desprovista de un presupuesto común, lo cual niega toda posibilidad de "contrato enunciativo", hecho que se revela como elemento transgresor, incapaz de configurar una comunicación identificatoria entre los hablantes. Si la indiferencia o la burla de la mujer introduce cierto vértigo disolutivo que desestabiliza a Andrés, las señales de amenazantes fracturas se acrecientan al interior del mismo espacio sacro, cuando de las místicas intenciones del joven se sirven, inclusive, los más "místicos" personajes:

SACERDOTE: Cada día cantas mejor Andrés, es un don celestial. A través de la palabra el Señor nos habló; las cuerdas vocales junto al corazón son las partes más divinas del cuerpo... (En la puesta en escena, el sacerdote caricia el sexo de Andrés).

ANDRÉS: Apriételo más fuerte.

SACERDOTE: No se trata de destruirlo, sino de vencerlo.

ANDRÉS: Llevamos haciendo este exorcismo por meses y aún no siento la purificación. (24)

La situación comunicativa que compromete a Andrés y al sacerdote, como co-productores de discurso, resulta ambigua. Esto, porque el religioso transgrede el principio de cooperación mediante su actitud, la cual evidencia cómo las aspiraciones de santidad de Andrés las maneja en favor de su impudicia lasciva. El muchacho siente la brecha entre la imagen que se ha construido, alrededor del ideal que promueve, y un mundo dudosamente sintonizado en torno de ese ideal; una sensación de estar expuesto al vacío, de movimiento errático y contradictorio, recorre al personaje.

¿Cómo conjugar lo que para Andrés es verdadero e inmutable con la vorágine de la contingencia, que se empeña por derrumbar las grandes certezas con signos fisurantes? En este sentido, resulta sintomático el camino trazado por Esteban, porque con él y sus acciones se perfila una voluntad que busca 
Ascesis y martirio de fin de siglo: una lectura de Éxtasis, creación dramática de Ramón Griffero / Jorge Rueda Castro

indirectamente la nulidad de proyecto de Andrés al instaurarse como su contraste: "No estamos en la Edad Media, me basta con decírtelo, yo voy a vivirlo todo, gozar cada día..." (52)

En efecto, desde el momento en que el propósito de Esteban -la sexualidad en la versión de máximo rendimiento-se configura como la antítesis del proyecto asceta de Andrés, ninguna circunstancia vivida por ambos puede ser comentada sin relacionarse con su antecedente causal el que, paradójicamente, actúa en el texto como su contraparte. La obra, con esto, ofrece otro descentramiento pues supone la ausencia de una visión vertebral; sí, en oposición, dos sendas, dos opciones y dos perspectivas.

Por otra parte, la "diferencia" socava la pretensión de un valor absoluto, cuando Andrés decide experimentar el amor de María, la empleada, porque... "está claro, en el amor está el sufrimiento" (26). No obstante, el deseo de amor sublime que pretende el joven deriva en el amenazante desenfreno del cuerpo, estableciéndose un diálogo con el proyecto de Esteban, al tiempo de cargarlo de ambivalencias y contradicciones internas. La carne reprimida, en una cultura que idolatra lo corporal y lo sensual, se expresa y aumenta la culpa. La tentación toma conciencia de su cuerpo,

Andrés solo. Comienza a masturbarse desaforadamente (Acotaciones).

No, no quiero, detén mi mano, por favor, detén mi mano! Estertores infames (acaba) Líquido inofensivo que pareces leche materna, pero que no nutres más que el placer de un pedazo de carne. Aquí en mi interior fermentan las garras del mal. (28)

La senda recorrida hasta ahora por el protagonista ha sido incierta y perspectivizada por una época y tiempo históricos que no garantizan correspondencia plena con el ideal del muchacho. Una cultura indiferente al proyecto de ascetismo sacro, desnuda los testimonios del portador, de aquí que la segunda unidad de lectura -El tormento-agrega otro aspecto que, sin cambiar el proyecto básico de Andrés, lo reordena y le da un significado aún más doloroso y de mayor intensidad dramática.

Los hechos que constituyen este segundo núcleo, se refieren derechamente a la humillación y martirio del cuerpo, donde el protagonista se concentra en alcanzar un estado de debilitamiento que lo convierte en víctima de la autoagresión: "Subyugaré a esta carne, que se contamina con las células del deseo" (31). Este hecho resulta clave para el desarrollo del texto, pues constituye un segundo efecto disolvente en el protagonista. Descubre que tal camino no alivia el desgarramiento interno que le provoca la persistente búsqueda; por el contrario, acentúa la sensación de extravío, de desgaste, de cansancio. Da la impresión de que el entorno social se resiste a confirmar su ideal, hecho que provoca en el sujeto otro desplazamiento. 
Aparece, en consecuencia, una tercera apuesta que puede promover energías inéditas para paralizar en parte la incertidumbre que va en aumento:

ANDRÉS: Me he dado cuenta que esta no es la senda que debo seguir, me han infectado los clavos y si esta vehemencia de la carne es tan fuerte es porque Él me está indicando otro camino. Quiere que me enfrente con el mal. Debo vencer al demonio que inunda nuestra tierra.

Iré a la calle, enfrentaré la ruindad, los vicios que se ha apoderado de tu reino. (35)

Guiado ahora por un delincuente, el Andrés de la tercera unidad de lectura - La perversión - descubre el carácter espurio de la realidad: violencia, excesos, droga. Una realidad ni buena ni mala, ni veraz ni falsa, ni singular ni anónima. Las vidas precarias con las cuales se vincula, las situaciones descarriadas que experimenta -aun tortura y asesinato- son indicios de la crisis que padecen los sujetos ante la pérdida de todo fundamento. La conciencia de la muerte pone en primer plano la necesidad de volver a indagar en el sentido de la vida al interior de una cultura de crisis: "Siento que mis pies se hunden en el fango, mis manos transpiran, y se vuelven garras negras. Al fin he llegado al centro de las tinieblas". (45)

La revelación del infierno urbano clausura la pesadilla vivida por Andrés. A partir de este instante, el síndrome de la alienación cobra apariencia en el personaje y con esto desaparece el concepto de identidad adscrito a un ideal macro. El sujeto se convierte en una caricatura engañosa que promueve la ambigüedad y el desorden mental.

La figura central, en las últimas páginas del texto, sugiere la imagen de un enajenado que ha tomado a la religión como la utopía capaz de encausar de manera ritual su demencia y extravío. No obstante, se trata de una sugestiva metáfora de la desintegración de Andrés, producto de la confusión acarreada por la búsqueda sin éxito de la trascendencia, porque el mismo entorno la ha dado -desde las sendas iniciales- por desaparecida. Desbaratado en la existencia cotidiana (desde la infancia misma), Andrés, arrojado en el mundo, no halla su lugar en él para sus ideales.

\section{Sendas extraviadas}

De este modo, Andrés en la I unidad de lectura -La búsqueda- permitía discernir entre ideas verdaderas de otras falsas, entre convicciones y apariencias. En este momento de la obra se percibía macizo en su identidad. Creía conocer, y apostó por ello al sentido profundo del hombre; deducía de aquí el fundamento que guiaba su historia vital, declarándose "sujeto trascendental" por cuanto se presumía dotado de una moral de validez universal. Con la imagen de un "yo consistente" en sus atributos y convincente, Andrés se aventura por la vida y 
Ascesis y martirio de fin de siglo: una lectura de Éxtasis, creación dramática de Ramón Griffero / Jorge Rueda Castro

enfrenta el devenir con un ideal providencialista y redentor. El proyecto de inscribir su "pequeña historia" en un "gran relato" conllevaba también el anhelo de sustancialidad interna, coherencia y continuidad.

El tormento (II unidad de lectura propuesta en el desarrollo de este ensayo), mostró hasta dónde Andrés extrema la voluntad para inscribir su vida personal en una totalidad unitaria, pero con la cultura de fin de siglo se ha instalado el descrédito y relativización de paradigmas.

La perversión -la última unidad-se compone de sordas derrotas del sujeto, pues el entorno impugna las pretensiones totalizantes y el recorrido del protagonista se desgasta en el colapso, la indeterminación del futuro y en la proliferación del relativismo ético. El personaje del Asaltante se lo gritará mientras Andrés vive las experiencias más oscuras en la ciudad: "Qué te preocupai tanto... Acaso cuando los milicos le abrían las guatas a los nachos o los ahogaban en la mierda, alguien les dijo algo... No sigai hablando tonteras, si aquí nadie es malo o bueno, somos no más". (45, énfasis mío)

El sentimiento de carencia de todo valor le hace descubrir que no hay meta alguna ni finalidad en la existencia; la unidad totalizadora se niega a través de la pluralidad de personajes solitarios, segregados, desquiciados o viciosos que desfilan ante sus ojos: La brutalidad asesina de El Asaltante (pp.37-42); la obscenidad orgiástica de El hombre del Parque (pp. 40-43); la lascivia denigrante de El Travesti (pp. 44-46); el delirio ciego de La Señora, quien ve en Andrés a su hijo muerto (pp. 47-49) y el placer sádico de El Capitán de Ejército, que induce a Andrés para que torture y fusile (pp. 55-57).

El estado al cual ha llegado el protagonista tiene ahora su equivalencia en Esteban, la otra figura relevante. No parece casual que este personaje haya transitado por una senda que resultó ser, igualmente, un salto al vacío:

Unos quieren ser héroes, otros santos, parece que todos necesitamos morir con alguna aureola en el cráneo... Soy positivo, me lo dijo un doctor que es lo mismo que estar poseído, nadie puede curarme. (46)

La senda por la cual transitó Esteban, la pasión erótica, se extravió en el SIDA; el cuerpo se incorpora, de este modo, con una significación tutora en la cultura sexual de fin de siglo, donde las palabras, las ideas, las sensaciones se contagian. Proyectos abstractos, de alcance metafísico, como aspiraciones particulares y concretas, de gozo casi lúdico, no son sino movimientos perdidos en los que no hay algo absoluto que los trascienda.

El cuerpo connota, de este modo, una de las verdades sociales e históricas fundamentales sobre la sexualidad de fin de siglo. Más allá de su significación concreta, el SIDA se convierte en una potente metáfora de nuestra cultura sexual: es un signo de la creciente confusión y ansiedad acerca de los cuerpos y lo hace significativo culturalmente hablando. Las enfermedades del cuerpo, 
sus debilitamientos - notoria imagen en la obra- son, sin duda, síntomas que se deben considerar a la hora de ofrecer interpretaciones sobre la cultura occidental de fin de siglo, y que marcan en el sujeto, se podría agregar, el estigma del error, de la sospecha, del debilitamiento, del desencanto.

Hacia el final del texto, las imágenes de los cuerpos de Andrés y Esteban adquieren la densidad connotativa que posibilita acotar una lectura en sintonía con el entorno cultural que marcó los años postreros del siglo. La experiencia última de ambos personajes conlleva la figura del vitalismo arruinado. Como resulta imposible alcanzar los fines por el solo deseo, el cuerpo es una condición necesaria de la acción en el mundo y distingue, con esto, el anhelo de la voluntad, el sueño del acto, lo utópico de lo real.

Por un lado, el discurso de la moralidad desplazó las energías creativas contra sí mismas: "Andrés en una silla metálica, con electrodos en su cráneo recibe descargas eléctricas" (Acotaciones, 60). Por otro, el discurso que sustentaba el erotismo como signo de la trascendencia, no pudo revertir la dimensión negativa de las energías: "Miro por la ventana y amo los rayos del sol, me fascino de ver cómo se mueven los cuerpos y me da envidia ... En lo único que creo, es en el virus que se nutre de mi sangre". (5)

Mientras las figuras centrales posibilitaban la búsqueda y, en consecuencia, construían utopías; el cuerpo aparecía como síntesis entre vida y acción, en una relación significativa con el mundo, porque era el correlato en movimiento de las posibilidades de un futuro trascendente. Ahora, la mente alienada de Andrés profundiza la turbación y la incertidumbre a través de imágenes alucinadas; su cuerpo linda con el paroxismo: "(Mientras recibe descargas eléctricas) ¡Que traigan al Santo Padre, a la comisión de los santos, que atestigüen los milagros!... (Descarga) ¡Que traigan al obispo del condado! En este lugar construiréis su Iglesia...(Descarga) ..." (60).

Paralelamente, el Esteban agónico, que tiende su cuerpo con llagas "sobre una sábana blanca", se convierte en signo de la inmovilidad, una metáfora del cuerpo (Muñoz, 2004) percibido sólo como carne inerte, negada en cuanto a la posibilidad de construir futuro, condicionada, en fin, a convertirse en cadáver.

Plantearse la existencia a los modos de Andrés y Esteban implica desplazarse por las sendas del conflicto no resuelto entre realidad e idealidad. Dar y sacrificar la vida por una ilusión, situación simbolizada en la negación de la cordura (Andrés) o en el cuerpo infecto (Esteban), en aras de una ideal con pretensiones absolutas y universales, ya Dios, ya erotismo, aparecen como formas contrastadas de lugares de desintegración, donde la existencia se muestra dos veces fallida, borrando certezas, alterando los centros, disipando las convicciones que hablan de esencias y de lo que se creía verdadero. 
Ascesis y martirio de fin de siglo: una lectura de Éxtasis, creación dramática de Ramón Griffero / Jorge Rueda Castro

\section{Conclusiones}

El análisis precedente mostró que Éxtasis o La senda de la santidad refleja las condiciones de un momento histórico marcado por la incertidumbre, el delirio y el dolor. Estos ámbitos promueven, reproducen y consolidan un horizonte cultural desprovisto de valores estables, así en lo socio-político como en lo religioso. Andrés y Esteban son figuras que divagan en medio de este des-orden precario con el marcado anhelo de volverlo un orden sustentado sobre creencias perennes. Sin embargo, las peculiaridades del entorno de los años noventa, han borrado la permanencia y trascendencia del sujeto como eje y dador de sentido del mundo. Los años iniciales del siglo XXI no muestran un cambio al respecto. La vigencia de la obra, en consecuencia, se manifiesta en la forma cómo los personajes protagónicos se extravían, comunicacional y accionalmente, al interior de sus proyectos. Se vuelven -por lo mismo- víctimas simbólicas de una matriz cultural cargada de titubeos, fragilidades y fracturas. Frente a esto, la intimidad, como último refugio, acusa el efecto de la desorientación. La muerte y la enajenación de Esteban y Andrés, respectivamente, sobrepasan los anhelos de orientación histórica y afectiva, cualitativamente distintos de aquéllos que la realidad determina, sentenciándolos irreversiblemente a la dispersión. La obra da cuenta de este proceso a través de la relación dinámica entre ella y el contexto cultural inscrito.

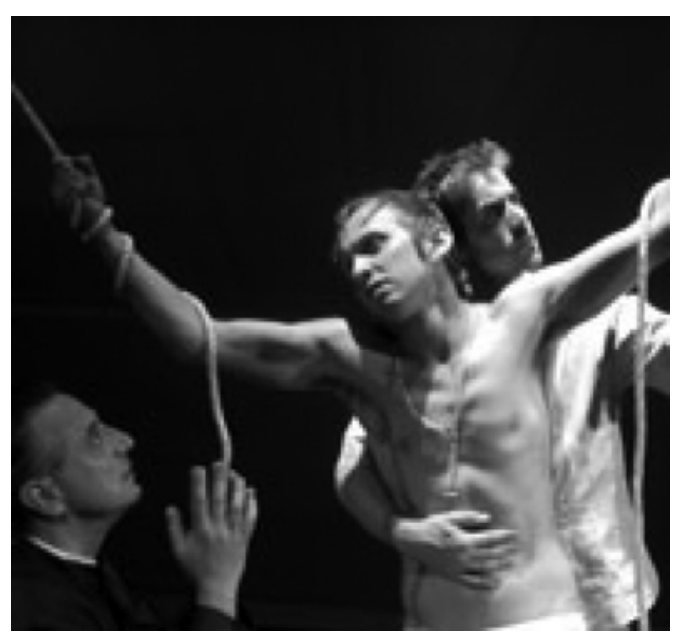

¿Que traigan al Santo Padre, a la comisión de los santos, que atestigüen los milagros!... ¿Que traigan al obispo del condado! En este lugar construiréis su Iglesia... (Andres, Éxtasis, 60). 


\section{Bibliografía}

Griffero, R. (1999). Extasis. Recuerdos del Hombre con su tortuga. Santiago de Chile: Dolmen.

Hopenhayn, M. (2004). Ni apocalípticos ni integrados. Aventuras de la modernidad en América Latina. Santiago: Fondo del Cultura Económica.

Larraín, J. (1996). Modernidad, razón e identidad en América Latina. Santiago: Andrés Bello.

Lyotard, J-F. (1986). La condición postmoderna. Trad. Mariano Antolín Rato. Madrid: Cátedra.

Muñoz, C. "Poética del cuerpo: Éxtasis o las sendas de la santidad de Ramón Griffero". Cyber Humanitatis $\mathrm{N}^{\circ} 29,2004$. Registro consultado con fecha 25 de junio de 2010, en http://www.cyberhumanitatis.uchile/ CDA/texto_sub_simple2 [ Links ]

Paz, O. (1987). Los hijos del Limo. Barcelona: Seix-Barral.

Pereira, P.: "Ser santo y morir en el intento". Diario La Época. Santiago de Chile 31.10.1994:33

Piña, J.: "Éxtasis". Revista Mensaje No 434 (1994). 57

Reyes, G. (1990). Pragmática lingüística. Barcelona: Montesinos Editores.

Van Dijk, T. (1999). Ideología. Una aproximación multidisciplinaria. Barcelona: Gedisa.

Vattimo, G. (1994). En torno a la posmodernidad. Barcelona: Anthropos.

Weeks, J.: "The body and sexuality" en Stuart Hall (1997): Modernity, an Introduction to Modern Societies. U.K., Oxford, 1997, pp.364-368.

Zaliasnik, Y: "La necesidad apremiante de que la vida tenga sentido". Diario La Época. Santiago 29.07.1994: 27 